\title{
Discussion on Double-layer Responsibility Control System of Enterprise Environmental Cost
}

\author{
Shu $\mathrm{He}^{1}$, FengzhouWang ${ }^{1, *}$, and You $\mathrm{He}^{2}$ \\ ${ }^{1}$ College of Business Administration Jimei University, Xiamen 361021, China \\ ${ }^{2}$ College of Music and Dance Xihua University, Sichuan 610000, China
}

\begin{abstract}
Based on the inside and outside area of the enterprises, this paper re-constructs the double-layer responsibility control system of enterprise environmental cost (DRSEC) by referring to life cycle theory, responsibility center theory and system theory. In the inner layer, each responsibility center of environmental cost control is divided according to the five stages of the enterprise life cycle. These responsibility centers closely cooperate to effectively reduce the environmental costs of the enterprises. In the outer layer, the two major responsible entities of the government and the public supervise the control of environmental costs, guide the goals setting of environmental costs and give feedback to inner layer. By designing a double-layer environmental cost control system with synchronous operation of inner and outer layers, we expect to provide new ideas for enterprises to control environmental costs.
\end{abstract}

\section{Introduction}

With the acceleration of the industrialization process and the continuous development of the global economy, the tightening of resource constraints, serious environmental pollution, and degradation of ecosystems have caused widespread concern in various countries. At present, China's environmental pollution problem is gradually intensifying. Enterprises in this period should actively respond to the call of the state, shoulder the responsibility of protecting the ecological environment and increase the resources investment for environmental governance. However, in order to achieve profit maximization goals, enterprises have to weigh the costs and benefits of implementing environmental pollution control. Therefore, seeking a scientific, reasonable, feasible and effective enterprise environmental cost control model is an urgent problem to be solved. In view of the defects of the existing environmental cost control system in China's enterprises, this paper intends to construct a double-layer responsibility control system to make up for the shortcomings of the traditional environmental cost control model, achieve a win-win situation for both economic and environmental benefits of the enterprises and promote sustainable development of society, economy and environment.

\section{Environmental cost and enterprise environmental cost control}

\subsection{The concept of environmental cost and enterprise environmental cost control}

In 1998, the United Nations Intergovernmental Working Group of Experts on International Standards of Accounting and Reporting adopted the Positional Announcement on Environmental Accounting and Reporting. Based on the principle of being responsible for the environment, environmental costs refer to the costs of measures taken or required to manage the environmental impact of business activities, as well as other costs incurred by the enterprises in implementing environmental objectives and requirements. Specifically, the environmental costs include environmental protection costs, environmental testing costs, internal environmental failure costs and external environmental failure costs.

The meaning of enterprise environmental cost control is a management activity aimed at improving the economic and environmental benefits of enterprises through the use of a series of means and methods to control various factors in the process of enterprise environmental cost formation. In terms of time, environmental cost control not only focuses on the current environmental costs, but also predicts the environmental costs that may occur in the future. In terms of space, it not only includes the internal environmental costs of the enterprise, but also considers the external environmental cost of the enterprise as much as possible $[1,2]$.

\subsection{Current defects in enterprise environmental cost control}

The environmental pollution problem has been greatly valued by governments. However, enterprises still have many defects in environmental cost control and the results of environmental protection are not satisfactory. 


\subsubsection{Enterprises don't have a deep understanding of environmental cost control}

Compared with previous years, Chinese enterprises have gradually realized the seriousness of environmental problems and the urgency of environmental cost control. However, many enterprises have not yet formed the moral concepts of environmental responsibility, implementing "first pollution, then governance", ignoring the beforehand control of environmental costs and only paying attention to the environmental pollution costs brought about by the production stage of the enterprises. Chinese enterprises don't stand in the perspective of long-term development and ecological protection to consider how to conduct full process control of their environmental costs.

\subsubsection{Environmental cost control system is not perfect}

In recent years, with the introduction of innovative concepts such as green thinking, clean production and circular economy, and environmental cost control models such as enterprise life cycle and value chain, the environmental cost control system have been enriched. Throughout the research results in this field, many scholars only discuss the single-layer control of environmental costs from the perspective of the enterprise itself, without considering that the government and the public in the external area of the enterprise also play an important role in environmental costs control. The model of the double-layer control mechanism is missing. A few scholars have taken a step forward to try to build a multi-dimensional environmental cost control system including government, enterprises and the public. But this system does not involve close cooperation within the enterprise and synchronous coordination among the three responsible entities.

\subsubsection{Environmental cost responsibility system has not been established}

Affected by the traditional concept of cost control, enterprises don't realize that the control of environmental costs requires the participation of all internal employees. Every workshop, every department and even every employee of the enterprise should bear the responsibility of controlling environmental costs. At the same time, the responsibility for environmental cost control has not been clearly implemented and there is a lack of hierarchical budget, execution, assessment and report of environmental cost.

\subsubsection{Environmental cost assessment mechanism is not perfect}

Some scholars in China have conducted a preliminary discussion on the evaluation index of enterprise environmental cost control. Wang X Y discussed the evaluation indicators of product design, production, sales and scrapping stages separately in 2009[3]. Zhan S W uses fuzzy analytic hierarchy process to evaluate each link of environmental cost control and each factor involved and quantify the evaluation results of enterprise environmental cost control in 2014[4]. Although the assessment indicators of environmental costs are constantly being revised, a set of scientific and reasonable evaluation indicators system that can be accepted by most enterprises has not yet been formed. The existing enterprise performance evaluation index system cannot objectively and fairly evaluate the employee performance of environmental cost control.

\section{Double-layer Responsibility Control System of Enterprise Environmental Cost}

\subsection{The connotation of DRSEC}

Based on the research results of relevant scholars, this paper builds a double-layer responsibility control system for enterprise environmental cost control. The control system is divided into two layers, the internal environmental cost control responsibility center (inner layer) and the external environmental cost control responsibility body (outer layer).

For general manufacturing enterprises, their life cycle is divided into five stages, namely design stage, production stage, sales stage, use stage and recycling stage. Each stage, each department, each work group and even individual in each stage is an environmental cost control responsibility center, which is given certain rights and assumes clear environmental cost control responsibility. Enterprises should set the overall goal of environmental cost control according to the environmental protection policies formulated by the state and local governments and in light of their own actual conditions, decomposes the overall goal of environmental cost control, implements it to each level of responsibility center and prepare the responsibility budget for each responsibility center. On this basis, each responsibility center should timely and accurately calculate and check the implementation of its environmental cost budget, so as to find out the deviation from the budget in time, analyze the reasons and take remedial measures. Subsequently, the performance of each responsibility center is analyzed and evaluated, so that its performance is closely linked to economic interests to form effective incentives and constraints. Finally, a work report will be generated. The information in the report is promptly fed back to each link to make corresponding adjustments. For non-manufacturing enterprises, the division of environmental cost control responsibility center is more flexible. Although its environmental cost is much less than manufacturing enterprises', it must establish awareness of environmental protection, enhance the sense of responsibility of ecological environment and actively participate in environmental pollution control to achieve commitment to energy saving and emission reduction [7-9]. 
Ecological civilization construction and environmental protection are not only simple pollution prevention problems, but also a development road problem, economic structure problems, and consumption patterns in essence. Therefore, it is necessary for the government, enterprises and the public to participate in solving the problems faced by economic, social development and environmental protection $[5,6]$. Outside the enterprise, the government and the public are the responsible subjects of environmental cost control. The government conducts macro-control and guidance on the overall goals of enterprise environmental costs. The consumption concept and behavior of the public directly affects the sales and use of enterprise products. The government and the public jointly supervise the entire environmental cost control within the enterprise. The enterprise timely feeds back the information obtained by the internal cycle of its own environmental cost control to the government and the public outside the enterprise and realizes the loop of environmental cost control of the inner and outer layers.

\subsection{Characteristics of DRSEC}

\subsubsection{The characteristic of entirety}

DRSEC is an entirety which consists of the government, the public and every department, workshop, and each employee in the enterprise. The system is not a simple sum of the elements. The inner layer of the system is coordinated by the responsibility centers formed by departments, workshops and employees, and interacts with the outer layer of the system to achieve the purpose of reducing the environmental cost of the system. However, this purpose cannot be achieved under the isolation of various elements. The various responsibility centers don't cooperate with each other, don't coordinate with the enterprise as a whole and the enterprises does not have the supervision of the government and the public, which may lead to the emergence of one-sided pursuit of profits while ignoring environmental costs .

\subsubsection{The characteristic of purpose}

System purpose refers to the specific functions that the system has for achieving its intended purpose. Each system has special function, which is the main indicator of system differentiation. The main purpose of the DRSEC is to reduce the environmental cost of Chinese enterprises through the simultaneous operation and close cooperation between the internal responsibility centers and the external responsible entities. In the whole process of the generation and development of the DRSEC, its purpose will not change and always reflects the general trend and general tendency of the development of the system.

\subsubsection{The characteristic of coordination}

The coordination of the DRSEC firstly reflects the close coordination between the inner and outer layers. The system assigns the same weight to both layers, allowing it to control the environmental costs simultaneously. The outer layer supervises and guides the inner layer. The inner layer promptly feedbacks. They coordinate with each other to form a two-way interactive circuit, which reduces the environmental costs of the enterprise. Secondly, when there is a contradiction between the specific objectives of each level of responsibility center of the DRSEC, it is necessary to carry out level-by-level coordination from the purpose of the system.

\subsubsection{The characteristic of hierarchy}

The DRSEC is divided into two layers, internal and external. The external responsibility body includes the government and the public. The inner layer divides the responsibility centers according to the life cycle stage. Each stage of the responsibility center can be decomposed at different levels. Each responsibility center undertakes certain environmental cost control responsibilities.

\section{Structure and content of the DRESC}

As shown in Figure 1, the left side represents the outer layer of the environmental cost double-responsibility control system, namely the government and the public, and the right side represents the inner layer of the control system, which is the responsibility centers of each stage.

The cost of product lock-in in the product development and design phase accounts for $75 \%$ to $90 \%$ of the total cost, so the environmental cost control during the product design phase should be emphasized. Enterprises should establish the concept of source control and eco-friendly design, comprehensively consider the possible impact of products on the environment in the product research and design process and organically integrate the concept of improving resource utilization efficiency and environmental protection benefits throughout the product life cycle. The traditional "high-mining, low-utilization, high-emission" extensive production mode must be abandoned decisively. Enterprises should implement green procurement and clean production, increase the recycling rate of waste and reduce the emission of environmental pollutants. At the same time, it is important to establish a green marketing system and recycling system actively to build an environmentally friendly image.

The government environmental protection department, on behalf of the state, exercises the duties assigned by laws and regulations to supervise the behaviors of all units in the use of energy resources and pollution prevention, imposes administrative penalties on discovered illegal acts and guides the establishment of environmental cost targets. The purpose is to achieve a balance between social environmental costs and economic benefits and to achieve a harmonious development of nature, economy and society. The public's consumption concept and consumption behavior directly affect the sales of enterprise products. The public 
should establish environmental protection awareness and the concept of "green consumption", guiding enterprises to provide "green products" to realize energy resource conservation and reduction through "green recycling", environmental protection and environmental cost control.

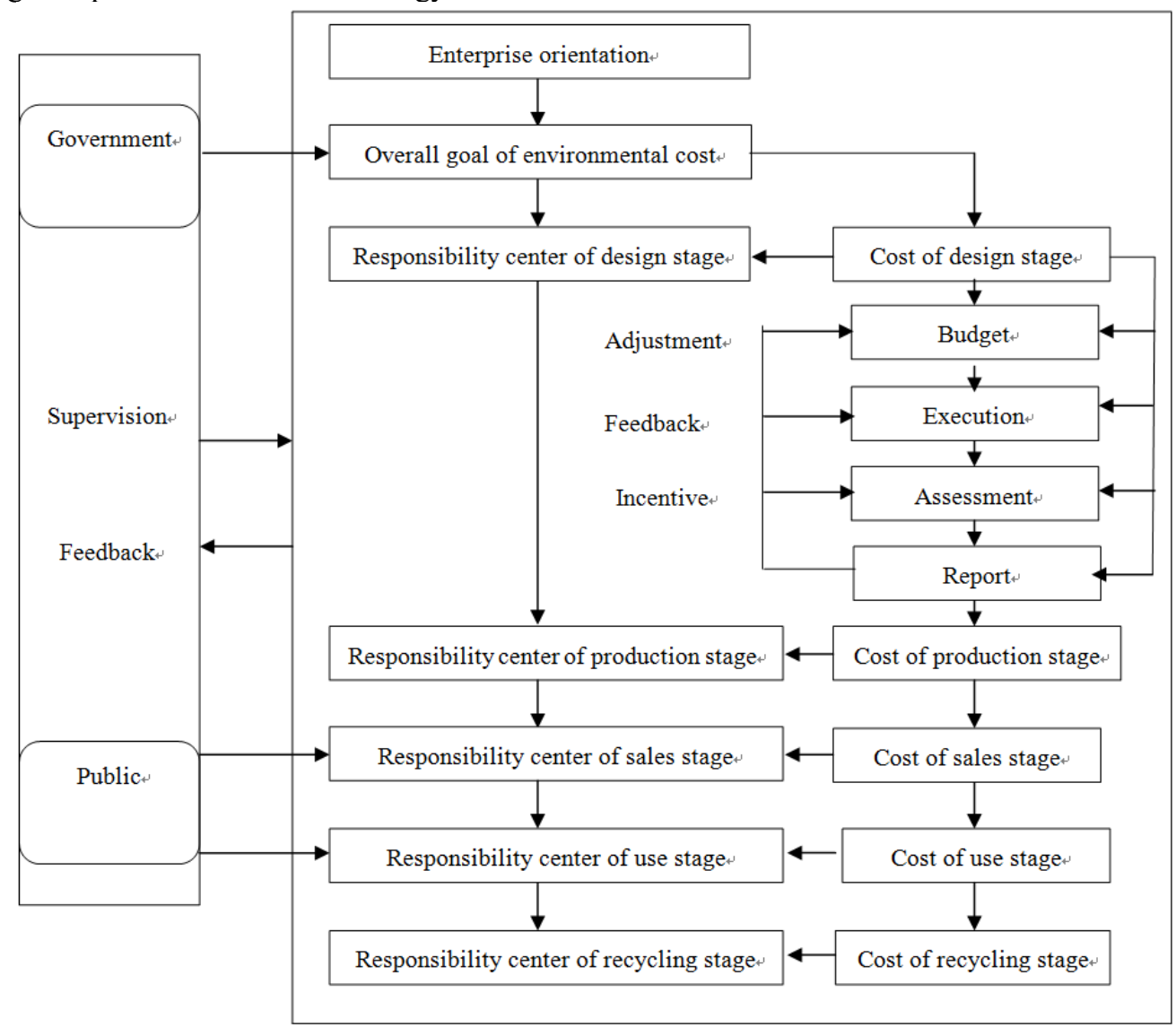

Fig.1. Structure diagram of DRSEC

\section{Conclusion}

At present, the Chinese government has vigorously called for and formulated policies to strengthen environmental protection and reduce environmental pollution. In view of the current problems such as lack of deep understanding of the company's environmental cost control and the imperfect environmental cost control system, this paper re-constructs the double-layer responsibility control system of enterprise environmental cost control by referring to life cycle theory, responsibility center theory and system theory. At the inner level, the responsibility centers at each level cooperate and coordinate. In the outer layer, the government and the public supervise the control of environmental costs, guide the goals setting of environmental costs and give feedbacks to inner layer.

The inner control layer of the responsibility control system cooperates with the outer layer and operates synchronously to reduce pollution emissions, save resources and realize natural, economic and social sustainable and harmonious development.

\section{References}

1. Q.L. Fu, CA, 28, 7-8(2011)

2. X.Q. Zheng, EE, 06, 53-55(2011)
3. X.Y. Wang, AN, 14, 137-138(2009)

4. S.W. Zhan, T. Jiang, FA, 11, 24-28(2014)

5. Z.J. Ma, CCPA, 08, 66-71(2013)

6. J.B. Liu, FAN, 20, 93-95(2010)

7. J.M. Wu, Y.X. Zhang, FA, 10, 29-31(2009)

8. X.Y. Liu, FA, 06, 13-15(2018)

9. P. Liang, FAN, 22, 20-22(2011) 